\title{
Does Over-colonization of Klebsiella pneumoniae in the Gut Cause Obesity?
}

\author{
Gopal Nath ${ }^{1}$, Shweta Singh², Rajesh Kumar ${ }^{3}$
}

\begin{abstract}
Background and objectives: Gut microbes have been implicated in human weight gain and involve a few species of the Enterobacteriaceae family such as Klebsiella pneumoniae. We have tried to explore the effect of early colonization of the K. pneumoniae and subsequent eradication through bacteriophage therapy in rat pups on weight gain and loss.

Materials and methods: Three pairs of rats selected for mating were grouped separately. Group I having five pups were kept on a sterile diet. Five pups each belonging to group II and III were fed with K. pneumoniae. At the end of 10th week, the pups belonging to the group III were fed with $K$. pneumoniae-specific phages for 8 weeks. At the end of 30th week, group III were again fed with the bacterium, while group II received bacteriophage therapy for the next 8 weeks. The weight of each of the pups was noted every Monday of the week till the completion of the study. Results: There was significantly higher weight gain $(p<0.001)$ in the rats colonized by the bacterium $(50 \%$ higher) than those without the colonization by K. pneumoniae by the end of the seventh week. When the bacterium was eradicated using a specific bacteriophage cocktail orally, the mean weight decreased and became almost similar to that of the control rats in about 12 weeks.
\end{abstract}

Conclusion: The bacterial species K. pneumoniae, which is a saprophyte with voracious metabolic activities, may lead to more harvesting of energy from the food and in turn lead to obesity.

Keywords: Bacteriophage therapy, Charles Foster rats, Klebsiella pneumoniae, Obesity.

Journal of Gastrointestinal Infections (2021): 10.5005/jp-journals-10068-3048

\section{INTRODUCTION}

There has been a substantial increase in the prevalence of obesity among rural residents and older Indians since 1975 . $^{1}$ Consequently, obesity-related comorbidities, i.e., cardiovascular diseases, type-II diabetes, osteoarthritis, gallbladder diseases, backache, obesity-associated cancers, hypertension, breathlessness, including psychological disturbances, are on the increase. ${ }^{2}$ The etiopathogenesis of obesity is multifactorial. Various factors like genetics, economic, psychological, physical exercise, diet, reproductive, and pharmacological etc., have been proposed to contribute to the genesis of obesity. ${ }^{3-9}$ The human metagenome is considered a composite of genes of Homo sapiens and those trillions of microbes colonizing the body. ${ }^{10}$ The introduction of antibiotics for the last 70 years may have induced obesity as it affects the gut microbiome. ${ }^{11}$ Gut microbiota exerts many functions, such as stimulating effect on the intestinal epithelium, leading to the appearance of microvilli and mobility affecting the quantity of energy absorbed. ${ }^{11-14}$

It has been demonstrated that germ-free mice eat more but gain less weight than conventionally reared mice, indicating the importance of gut microbiota and weight gain. ${ }^{15}$ The transplantation of gut microbiota from discordant human twins to the two groups of germ-free mice ensued into the expression of the donor's respective phenotypic character again shows the significance of the type of gut microbiota on weight gain. ${ }^{16}$ Therefore, the new term has been coined as "Infectobesity."17 Gut dysbiosis in terms of preponderance of either Firmicutes or Bacteroides or Actinobacteria has been proposed in the causation of obesity; however, phylum-level differences of gut microbiota between lean and obese individuals may not be universally real. ${ }^{18}$ To establish the concept of "Infectobesity", we
${ }^{1-3}$ Laboratory for Gastrointestinal Infections, Department of Microbiology, Institute of Medical Sciences, Banaras Hindu University, Varanasi, Uttar Pradesh, India

Corresponding Author: Gopal Nath, Laboratory for Gastrointestinal Infections, Department of Microbiology, Institute of Medical Sciences, Banaras Hindu University, Varanasi, Uttar Pradesh, India, e-mail: gopalnath@gmail.com

How to cite this article: Nath G, Singh S, Kumar R. Does Overcolonization of Klebsiella pneumoniae in the Gut Cause Obesity? J Gastrointest Infect 2021;11:3-8.

Source of support: Nil

Conflict of interest: None

should try to determine etiological agent/s causing obesity. ${ }^{19}$ Chlamydiae trachomatis, Selenomonas noxia, Helicobacter pylori, Chlamydophila pneumoniae, and viruses, e.g. certain adenovirus, canine distemper virus, Borna disease virus, enteroviruses, and Herpes simplex 1 and 2, etc., have been implicated in the genesis of obesity. ${ }^{20,21}$

In a pilot study, we cultured stool samples from five lean and obese subjects. Interestingly, all the five stool samples from obese subjects yielded K. pneumoniae as a predominant growth, while this bacterium was absent from the samples of leans subjects (unpublished data). A few Chinese studies claim that K. pneumoniae and Enterobacter cloacae have been associated with nonalcoholic fatty liver disease in human being ${ }^{22}$ and enhanced subcutaneous fat accumulation in rats. ${ }^{23}$

With this background, we have planned to explore the effect of K. pneumoniae colonization and its eradication by using its specific bacteriophage cocktail on weight gain or loss in an animal model.

() The Author(s). 2021 Open Access This article is distributed under the terms of the Creative Commons Attribution 4.0 International License (https://creativecommons. org/licenses/by-nc/4.0/), which permits unrestricted use, distribution, and non-commercial reproduction in any medium, provided you give appropriate credit to the original author(s) and the source, provide a link to the Creative Commons license, and indicate if changes were made. The Creative Commons Public Domain Dedication waiver (http://creativecommons.org/publicdomain/zero/1.0/) applies to the data made available in this article, unless otherwise stated. 


\section{Materials and Methods}

The Institute Animal Ethics Committee of Banaras, Hindu University, approved the experimental protocol (Dean/2018/C.A.E.C./821 dated August 29, 2018). This study was carried out from July 2019 to May 2020.

\section{Study Design}

Three pairs of Charles Foster adult male and female rats were selected for mating. The selected rats did not have prior colonization of $K$. pneumoniae in their gut, as proved by culturing stool samples on MacConkey agar. All three pairs of rats were fed ad libitum with a standard chow diet and sterile drinking water. The animals were divided into three groups:

Group I: This group comprised the five pups delivered from the mother who was only on a standard chow diet and sterile drinking water.

Group II: In this group, the five pups delivered from the mother who was given K. pneumoniae in the drinking water at the final concentration of $10^{9} \mathrm{CFU} / \mathrm{mL}$ since put for mating were included. The bacterial feeding was continued up to 10 weeks after birth. The bacteriophage cocktail was initiated at the concentration of $10^{12} \mathrm{PFU} / \mathrm{mL}$ at the end of 30th week and continued for further 2 weeks.

Group III: This group consisted of the four pups delivered from the mother who was given $K$. pneumoniae in the drinking water at a final concentration of $10^{9} \mathrm{CFU} / \mathrm{mL}$ since put for mating. The bacterial feeding was continued up to 10 weeks after birth. The bacteriophage cocktail at a concentration of $10^{12} \mathrm{PFU} / \mathrm{mL}$ was initiated at the end of 10th week and continued for further 2 weeks. At the beginning of 31st week, the rats belonging to this group were again fed with $K$. pneumoniae at a final concentration of $10^{9} \mathrm{CFU} / \mathrm{mL}$ for 8 weeks.

The weight of each of the experimental animal was recorded every Monday of the week. Blood samples were collected from the retro-orbital vein of the rats at the end of 30th week to estimate serum urea, creatinine, cholesterol, triglyceride, high-density lipoprotein (HDL), low-density lipoprotein ( $L D L)$, very-low-density lipoprotein (VLDL), serum glutamic oxaloacetic transaminase (SGOT), serum glutamic pyruvic transaminase (SGPT), total bilirubin (TB), and direct bilirubin. These parameters were estimated by using the Johnson \& Johnson-4600 Chemistry System Autoanalyzer (Mumbai, India) working on the principle of Dry Chemistry Technology.

\section{Isolation of $K$. pneumoniae Strains}

A total of 100 isolates of $K$. pneumoniae were isolated from clinical and environmental samples. These isolates were used to test specific bacteriophage activity in order to pick up the three most lytic phages for the strain used for feeding the rats. One isolate of K. pneumoniae (Kpnob01) from an obese individual was isolated and identified. This isolate was suspended in normal saline at a concentration of $10^{9} \mathrm{CFU} / \mathrm{mL}$ and was given to the animals in the study through drinking water.

\section{Isolation of Bacteriophages}

For isolation of respective bacteriophages, water specimens in the volume of $100 \mathrm{~mL}$ were collected from different sources like hospital sewage, river Ganga, ponds, sewer of the municipal corporation, etc. The water was centrifuged, and the supernatant was collected and treated with $1 \%$ chloroform for 10 minutes.
The lawn culture of the different isolates of $K$. pneumoniae was brought into the log phase by incubating for 4 hours in a $90 \mathrm{~mm}$ Petri plate. The chloroform-treated water was poured on each plate in the volume of $2 \mathrm{~mL}$ and incubated overnight at $37^{\circ} \mathrm{C}$ for plaque formation. If plaques were not seen, the surface of the plate was washed with $5 \mathrm{~mL}$ Tris-Magnesium chloride buffer ( $\mathrm{pH}$ 7.0). The washing obtained was centrifuged and treated with $1 \%$ chloroform to lyse the bacteria and to spare the protein-coated viruses. The supernatant was then dropped on fresh lawn culture of the host bacterium in the log phase. After overnight incubation the plaques seen with different morphology were cut and propagated on the host bacterium. The number of phages was increased by inoculating a larger surface area of the host bacterium lawn culture on Roux bottles. The sufficient volume of the harvest was subjected to membrane dialysis at $4^{\circ} \mathrm{C}$ with three changes of $25 \%$ polyethylene glycol buffer three times. The purified phages were suspended in normal saline to have ready to use phages at the concentration of $10^{12} \mathrm{PFU} / \mathrm{mL}$.

\section{Statistical Analysis}

Statistical analysis was done using SPSS trial version 21.0 software. For comparing the mean values among the groups, ANOVA, and between the two groups, Student's $t$-test, have been used, if the data followed the Gaussian distribution. If the data did not follow the normality, the Wilcoxon signed-rank test and the KruskalWallis test were applied. If ANOVA/Kruskal-Wallis tests resulted in significant differences, a post-hoc test (Student-Newman-Keuls) was used to determine pairwise differences. The critical value of $p$ indicating the probability of significant difference was taken as $<0.05$ for comparisons at two-tailed tests.

\section{Results}

At the beginning of the experiment, none of the stool samples collected from six adult rats yielded K. pneumoniae. Table 1 and Figure 1 show that the weight of the pups in all the three study groups was similar at birth. At the end of 7 days, the mean percentage weight gain in groups II and III was 4.8 and 10.1, respectively, compared to group I. The highest percentage of weight gain was observed in the rats fed with $K$. pneumoniae (groups II and III) than the control (group I) during the sixth and seventh weeks (55.7-62.9\%, respectively). At the end of the 10th week, the overall percentage of weight gain was 18.4 in group II and $13.3 \%$ in group III. The mean percentage weight gain (18.4) was significantly higher in rats fed with K. pneumoniae (group I vs group II; $p<0.021$ ).

Interestingly when the bacteriophage cocktail therapy was started at the end of 10th week and continued for 15 days, the mean weight of the intervention group III decreased $(220.7 \mathrm{~g})$ and was comparable $(p=0.772)$ with the mean weight of the control group ( $229 \mathrm{~g}$ ). K. pneumoniae could not be isolated from the stool samples after 1 week of the phage therapy. However, the phage therapy was continued for 8 weeks, and comparable weight could be seen in both groups I and III. Interestingly K. pneumoniae was observed continuously getting excreted by all the rats of group II. At the end of 30th week, the mean weight in the control group was $228 \mathrm{~g}$, while those on $K$. pneumoniae were $288 \mathrm{~g}$, which was $26.3 \%$ higher $(p<0.029)$. The mean weight of group III was $2.8 \%$ less at the end of 30th week. However, the mean weight difference between groups I and III was statistically comparable $(p>0.5)$. 


\begin{tabular}{|c|c|c|c|c|c|}
\hline Weeks & $\begin{array}{c}\text { Group I } \\
\text { (Control group) }\end{array}$ & $\begin{array}{c}\text { Group II } \\
\text { (K. pneumoniae + phage } \\
\text { therapy at 30th week) }\end{array}$ & $\begin{array}{l}\text { Group I vs group } \\
\text { II (\% weight gain/ } \\
\text { loss) }\end{array}$ & $\begin{array}{c}\text { Group III (K. pneumoniae + phage } \\
\text { therapy at 10th week + repeat } \\
\text { K. pneumoniae at 30th week) }\end{array}$ & $\begin{array}{l}\text { Group I vs group III } \\
\text { (\% weight gain/loss) }\end{array}$ \\
\hline 0 & 6 & 6 & 00 & 6 & 00 \\
\hline 1 & 16.8 & 17.6 & +4.8 & 18.5 & +10.1 \\
\hline 2 & 26.2 & 25 & -4.5 & 25 & -4.5 \\
\hline 3 & 29.4 & 41.9 & +42.5 & 42.25 & +43.7 \\
\hline 4 & 51.8 & 72.8 & +40.5 & 73.25 & +41.4 \\
\hline 5 & 69.4 & 99 & +42.6 & 108.75 & +56.7 \\
\hline 6 & 87.6 & 136.4 & +55.7 & 115.75 & +62.9 \\
\hline 7 & 97.6 & 151.8 & +55.7 & 142.75 & +62.9 \\
\hline 8 & 132.8 & 165.8 & +24.8 & 156.5 & +29.1 \\
\hline 9 & 142.8 & 180.2 & +15.2 & 171.5 & +15.8 \\
\hline 10 & 161.2 & 190.8 & +18.4 & 182.75 & +13.3 \\
\hline 11 & 168.8 & 209 & +23.8 & 174.25 & +9.9 \\
\hline 12 & 182.4 & 222.6 & +22.03 & 180.75 & -0.9 \\
\hline 13 & 193.6 & 237.6 & +22.4 & 181.5 & -6.1 \\
\hline 14 & 194.4 & 241 & +23.9 & 187.5 & -3.5 \\
\hline 15 & 197.2 & 255.6 & +29.6 & 192 & -2.6 \\
\hline 16 & 207.8 & 248 & +19.3 & 196.75 & -5.3 \\
\hline 17 & 207.4 & 251.8 & +21.1 & 200.25 & -3.4 \\
\hline 18 & 207.4 & 253.4 & +22.2 & 205.75 & -0.9 \\
\hline 19 & 207.8 & 265.6 & +27.8 & 219.25 & +5.5 \\
\hline 20 & 206.8 & 271.6 & +31.3 & 213.25 & +3.1 \\
\hline 21 & 202 & 275.2 & +36.2 & 217.75 & +7.8 \\
\hline 22 & 201.2 & 275.8 & +37.1 & 223.5 & +11.1 \\
\hline 23 & 211.2 & 279.2 & +32.2 & 220.25 & +4.3 \\
\hline 24 & 212.6 & 279 & +32 & 216.5 & +1.8 \\
\hline 25 & 213.2 & 282 & +32.3 & 221 & +3.6 \\
\hline 26 & 215.6 & 285.6 & +32.4 & 215 & -0.09 \\
\hline 27 & 226 & 279 & +23.4 & 223 & -1.3 \\
\hline 28 & 229 & 294 & +22.1 & 226.75 & -0.9 \\
\hline 30 & 228 & 288 & +26.3 & 221.5 & -2.8 \\
\hline 32 & 227.4 & 280 & +23.1 & 219.75 & -3.3 \\
\hline 34 & 230.8 & 259.25 & +8.0 & 219.75 & -4.8 \\
\hline 36 & 206 & 258.5 & +25.5 & 201.5 & -2.1 \\
\hline 38 & 222.4 & 208.5 & -6.2 & 154.4 & -30.6 \\
\hline 40 & 233 & 213 & -8.5 & 280 & +20 \\
\hline 42 & 230 & 223 & -3.0 & 283 & +23 \\
\hline 44 & 232.5 & 225.5 & -3 & 268.5 & +15.5 \\
\hline 46 & 235.2 & 213.75 & -9.1 & 280 & +19.1 \\
\hline
\end{tabular}

We did a reversal of therapy at the end of the 30th week. We administered bacteria to the rats on phage therapy (group III) and initiated phage therapy to those who were exclusively on bacteria (group II) up to 10 weeks; we observed a weight gain by $20 \%$ in group III in comparison to group I at the end of 38th week. However, group II, which was on phage therapy, lost weight and become comparable to the control group ( $p=0.168$ ) by the end of 8 weeks (Table 1 and Fig. 1). The percentage of weight gain in group III was observed to be 19.1. Contrary to this, group II had a weight loss of $9.1 \%$ compared to the control group I (Table 1). The other significant 


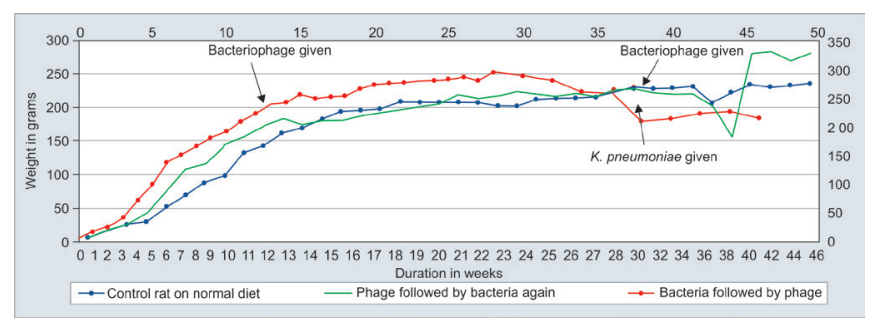

Fig. 1: Weight pattern of rats fed with $K$. pneumoniae and later treated with specific bacteriophage

observation was that one rat in group II died at the age of 32 weeks, weighing exceptionally high, i.e., $375 \mathrm{~g}$, while the average weight of the rest of the rats in group II was $260 \mathrm{~g}$ at 30th week.

The levels of cholesterol, LDL, and SGOT were the highest in group I. In group II, the highest level of SGOT, total bilirubin, and direct bilirubin was observed. Further, group II also had the best ratio of HDL/CHOL and TG/HDL. The HDL level in group II was significantly higher than group III $(p<0.029)$. The VLDL, however, was significantly higher in group III than group II ( $p<0.003)$. Further, the highest levels of TG and VLDL were observed in group III. Interestingly, the worst ratio between TG/CHOL was also observed in group II (Table 2).

\section{Discussion}

In this study, we observed that K. pneumoniae contributed to excess weight gain by rats made to colonize the bacterium in their gut. When the oral bacteriophage therapy eradicated the bacterial colonization of 10 and 30 weeks duration in rats, the weight loss could be observed on both occasions. The further surprising observation was that when the bacteriophage treated group of rats were again fed with fed $K$. pneumoniae, they gained a significantly higher weight $(p<0.5)$ than the control group in the next 16 weeks.

Reports indicate that bacteria may produce several metabolites that may affect the composition of the gut microbiota. The metabolites may enter the blood circulation and act on distant organs like the liver, the adipose depot, and even the brain. ${ }^{24}$ Pieces of evidence are available suggesting that certain bacteria do colonize the gut of obese persons, which may breakdown the food substrates (polysaccharides). These polysaccharides are usually undigestible by the flora available in lean subjects. These bacteria, if inhabited, may provide up to $40 \%$ more calories to the host for absorption and assimilation. Saprophytes can survive on simple carbon sources, e.g., citrate, nitrate, indigestible complex polysaccharides, etc. These saprophytes may produce various short-chain fatty acids (SCFA) like acetate, butyrate, and propionate as well as other metabolites (leptins, leptin receptor inhibitors, other neurotransmitters, trimethylamine, indole etc.), ${ }^{25}$ which may help in lipogenesis. These metabolites and neurotransmitters may stimulate the hunger center. The SCFA like acetate may lead to fat deposition. Acetate is known for its potential for increased lipogenesis. ${ }^{26}$

Further, these bacteria may also cause auto-brewery syndrome because of their high fermentative abilities leading to the adverse effect of alcoholism, apart from obesity. ${ }^{22}$ The authors have stated that alcohol drinkers following weekly low-risk drinking guidelines are not insulated from harm. ${ }^{27}$

We have to consider the present data with caution that K. pneumoniae may not be the only bacterium involved in excess weight gain. This is quite possible that other bacteria of saprophytic nature with good fermenting activity can cause more energy harvesting in the gut. The possible mechanism might be that these saprophytes can utilize even the citrate like simple carbon substrates. In support of this speculation, the plant Garcinia extract, hydroxy-citric acid, has been found to cause weight loss by competitively inhibiting the enzyme adenosine triphosphatase (ATP)-citrate-lyase. ${ }^{28-31}$ Cytosolic acetyl-CoA synthesized by ATP citrate lyase is the primary enzyme responsible in many tissues. Cytosolic acetyl-CoA is used in several critical biosynthetic pathways, including lipogenesis and cholesterologenesis. ${ }^{32}$ K. pneumoniae can utilize the citrate through a fermentative pathway involving carrier CitS, citrate lyase, oxaloacetate decarboxylase. ${ }^{33}$ K. pneumoniae is also known for bioconversion of pentose sugars of hemicelluloses to ethanol. ${ }^{34}$ Therefore, it is worth looking for the colonization of alcohol-producing bacteria in the human gut, which might cause all the adverse effect of alcohol consumption including weight gain despite being a teetotaler. The significance of the present work is that if a bacterial association is established with obesity; the culprit bacteria may be eradicated using specific bacteriophages.

Table 2: Showing lipid profile and liver function tests in different groups

\begin{tabular}{lcccc}
\hline & Group I (mean \pm SEM) & Group II (mean \pm SEM) & Group III (mean \pm SEM) & Significance \\
\hline Cholesterol $(\mathrm{mg} / \mathrm{dL})$ & $109.40 \pm 29.11$ & $87.80 \pm 32.51$ & $91 \pm 17.31$ & \\
TG $(\mathrm{mg} / \mathrm{dL})$ & $216.40 \pm 50.25$ & $137.60 \pm 74.40$ & $307.25 \pm 71.66$ & $2 \mathrm{vs} 3, p<0.003$ \\
$\mathrm{HDL}(\mathrm{mg} / \mathrm{dL})$ & $41.80 \pm 4.87$ & $37.00 \pm 6.44$ & $46.00 \pm 4.24$ & \\
LDL $(\mathrm{mg} / \mathrm{dL})$ & $24.32 \pm 35.77$ & $23.28 \pm 31.13$ & $16.20 \pm 19.73$ & \\
VLDL $(\mathrm{mg} / \mathrm{dL})$ & $43.28 \pm 10.05$ & $27.52 \pm 14.88$ & $61.45 \pm 14.33$ & $2 \mathrm{vs} 3, p<0.003$ \\
SGOT & $239.80 \pm 73.67$ & $162.20 \pm .20 .33$ & $138.75 \pm 33.95$ & \\
SGPT & $101.00 \pm 118.32$ & $112.60 \pm 98.50$ & $35.25 \pm 8.06$ & \\
Total bilirubin & $0.34 \pm 0.05$ & $0.44 \pm 0.22$ & $0.38 \pm 0.10$ & \\
Direct bilirubin & $0.10 \pm 00$ & $0.12 \pm 0.04$ & $0.10 \pm 0.00$ &
\end{tabular}

TG/HDL

HDL/VLDL

TG, triglycerides; HDL, high-density lipoprotein; LDL, low-density lipoprotein;VLDL, very low-density lipoprotein;SGOT, serum glutamic-oxaloacetic transaminase, SGPT, serum glutamic pyruvic transaminase 
The implication of the detection of the highest HDL level, the highest $\mathrm{HDL} / \mathrm{CHOL}$, and the lowest TG/HDL ratios in the rats on bacterial therapy needs explanation. However, the highest SGPT, along with elevated total bilirubin and direct bilirubin (an indicator of liver damage), indicates that prolonged colonization with K. pneumoniae may cause injury to liver parenchyma. In support of this statement, E. cloacae have been reported in inducing hepatic damage and subcutaneous fat accumulation in mice on a high-fat diet. ${ }^{35}$

In conclusion, significant advances have been made, and our understanding concerning obesity is improving. The data presented in this study are based on a minimal number of rats. The high SGPT in group II might be indicating liver damage. Contrary to this, the excellent ratio between $\mathrm{HDL} / \mathrm{CHOL}$ and $\mathrm{HDL} / \mathrm{TG}$ in group II may indicate that $K$. pneumoniae may help maintain these healthy ratios. The highest levels of TG and VLDL in group III remain to be explained. Therefore the experiment may be repeated with many more animals to have robust data about the relationship between $K$. pneumoniae colonization and obesity and also its amelioration by specific bacteriophages can be verified. Exclusive dietary foods are usually associated with unpredictable outcomes. Therefore, the ultimate aim is to develop a personalized intervention if the causative agent/s or factors are known. Specific bacteriophage therapy may be a significant modality in this direction. There is an in vitro study where feces treated with specific bacteriophage before transplantation prevented the development of nonalcoholic fatty liver disease. ${ }^{22}$ Our study is unique as we have fed the rats with the bacteria and eradicated it with a particular cocktail of phages, establishing the role of $K$. pneumoniae in obesity. However, a lot more is required to delineate the relationship between obesity and microbes and specific bacteriophage therapy. ${ }^{36}$

\section{ACKNowledgments}

The authors gratefully acknowledge the help in statistical analysis rendered by Prof TB Singh, Division of Biostatistics, Institute of Medical Sciences, Banaras Hindu University, Varanasi, Uttar Pradesh, India.

\section{References}

1. Luhar $S$, Timæus $I M$, Jones $R$, et al. Forecasting the prevalence of overweight and obesity in India to 2040.PLoS One 2020;15(2):e0229438. DOI: $10.1371 /$ journal.pone.0229438.

2. Dixon JB. The effect of obesity on health outcomes. Mol Cell Endocrinol 2010;316(2):104-108. DOI: 10.1016/j.mce.2009.07.00.

3. Kushner RF, Ryan DH. Assessment and lifestyle management of patients with obesity: clinical recommendations from systematic reviews. JAMA 2014;312(9):943-952. DOI:10.1001/jama.2014.10432.

4. Alamuddin NZ, Bakizada Z, Wadden TA. Management of obesity. J Clin Oncol 2016;34(35):4295-4305. DOI: 10.1016/S01406736(16)00271-3.

5. Burgess $E$, Hassmén $P$, Welvaert $M$, et al. Behavioural treatment strategies improve adherence to lifestyle intervention programmes in adults with obesity: a systematic review and meta-analysis. Clin Obes 2017;7(2):105-114. DOI: 10.1111/cob.12180.

6. Müller TD, Clemmensen C, Finan B, et al. Anti-obesity therapy: from rainbow pills to polyagonists. Lancet Infect Dis 2011;11:963-969. DOI: 10.1124/pr.117.014803. PMID: 30087160.

7. Lai KY, Sarkar C, Ni MY, et al. Exposure to light at night (LAN) and risk of obesity: a systematic review and meta-analysis of observational studies. Environ Res 2020;187:109637. DOI: 10.1016/j.envres.2020.109637.

8. Monda V, Villano I, Messina A, et al. Exercise modifies the gut microbiota with positive health effects. Oxid Med Cell Longev 2017;2017:3831972. DOI: 10.1155/2017/3831972.
9. Jha AR, Davenport ER, Gautam Y, et al. Gut microbiome transition across a lifestyle gradient in Himalaya. PLoS Biol 2018;16(11):e2005396. DOI: 10.1371/journal.pbio.2005396.

10. Qin J, Li R, Raes J, et al. A human gut microbial gene catalogue established by metagenomic sequencing. Nature 2010;464(7285): 59-65. DOI: 10.1038/nature08821.

11. Del Fiol FS, Balcão VM, Barberato-Fillho S, et al. Obesity: a new adverse effect of antibiotics? Front Pharmacol 2018;9:1408. DOI: 10.3389/ fphar.2018.01408. PMID: 30559670; PMCID: PMC6287021.

12. Stappenbeck TS, Hooper LV, Gordon Jl. Developmental regulation of intestinal angiogenesis by indigenous microbes via Paneth cells. Proc Natl Acad Sci U S A 2002;99(24):15451-15455. DOI: 10.1073/ pnas.202604299.

13. Vandeputte D, Kathagen G, D'Hoe K, et al. Quantitative microbiome profiling links gut community variation to microbial load. Nature 2017;551(7681):507-511. DOI: 10.1038/nature24460.

14. Park JS, Seo JH, Youn HS. Gut microbiota and clinical disease: obesity and non-alcoholic fatty liver disease. Pediatr Gastroenterol Hepatol Nutr 2013;16(1):22-27. DOI: 10.5223/pghn.2013.16.1.22.

15. Bajzer M,Seeley RJ. Obesity and gut flora. Nature 2006;444(7122):1009_ 1010. DOI: 10.1038/4441009a.

16. Ridaura VK, Faith JJ, Rey FE, et al. Gut microbiota from twins discordant for obesity modulate metabolism in mice. Science 2013;341(6150):1241214. DOI: 10.1126/science.1241214.

17. Dhurandhar NV. A framework for identification of infections that contribute to human obesity. Lancet Infect Dis 2011;11(12):963-969. DOI: 10.1016/S1473-3099(11)70274-2.

18. Bervoets L, Van Hoorenbeeck K, Kortleven I, et al. Differences in gut microbiota composition between obese and lean children: a crosssectional study. Gut Pathol 2013;5:10. DOI: 10.1186/1757-4749-5-10.

19. Casazza K, Brown A, Astrup A, et al. Weighing the evidence of common beliefs in obesity research. Crit Rev Food Sci Nutr 2015;55(14):2014-2053. DOI: 10.1080/10408398.2014.922044.

20. Voss JD, Dhurandhar NV. Viral infections and obesity. Curr Obes Rep 2017;6(1):28-37. DOI: 10.3390/biom9110726.

21. Hegde V, Dhurandhar NV. Microbes and obesity-interrelationship between infection, adipose tissue and the immune system. Clin Microbiol Infect 2013;19(4):314-320. DOI: 10.1111/1469-0691.12157.

22. Yuan J, Chen C, Cui J. Fatty liver disease caused by high-alcoholproducing Klebsiella pneumoniae. Cell Metab 2019;30(4):675-688. DOI: 10.1016/j.cmet.2019.08.018.

23. Fei $\mathrm{N}, \mathrm{Zhao} \mathrm{L}$. An opportunistic pathogen isolated from the gut of an obese human causes obesity in germ-free mice. Multidisc J Microbial Ecol 2013;7(4):880-884. DOI: 10.1038/ismej.2012.153.

24. Rastelli M, Cani PD, Knauf C. The gut microbiome influences host endocrine functions. End Rev 2019;40(5):1271-1284. DOI: 10.1210/ er.2018-00280.

25. Cani PD, Knauf $C$. How gut microbes talk to organs: The role of endocrine and nervous routes. Mol Metab 2016;5(9):743-752. DOI: 10.1016/j.molmet.2016.05.011.

26. Gao X, Lin SH, Ren F, et al. Acetate functions as an epigenetic metabolite to promote lipid synthesis under hypoxia. Nat Commun 2016;7:11960. DOI: 10.1038/ncomms11960.

27. Sherk A, Thomas G, Churchill S, et al. Does drinking within low-risk guidelines prevent harm? Implications for high-income countries using the international model of alcohol harms and policies. J Stud Alcohol Drugs 2020;81(3):352-361. PMID: 32527387.

28. Mattes RD, Bormann L. Effects of (-)-hydroxycitric acid on appetitive variables. Physiol Behav 2000;71(1-2):87-94. DOI: 10.1016/s00319384(00)00321-8.

29. Hayamizu K, Ishii Y, Kaneko I, et al. Effects of Garcinia cambogia (Hydroxycitric Acid) on visceral fat accumulation: a double-blind, randomized, placebo-controlled trial. Curr Therap Res 2003;64(8): 551-567. DOI: 10.1016/j.curtheres.2003.08.006.

30. Preuss HG, Bagchi D, Bagchi M, et al. Efficacy of a novel, natural extract of (-)-hydroxycitric acid (HCA-SX) and a combination of HCA-SX, niacin-bound chromium and Gymnema sylvestre extract in weight management in human volunteers: a pilot study. Nutr Res 2004;24(1):45-58. DOI: 10.1016/j.nutres.2003.09.007. 
31. Downs BW, Bagchi M, Subbaraju GV, et al. Bioefficacy of a novel calcium-potassium salt of (-)-hydroxycitric acid. Mut Res 2005;579 (1-2):149-162. DOI: 10.1016/j.mrfmmm.2005.02.021.

32. Robinson JA, Fersht AR, Gani D. Polyketide synthase complexes: their structure and function in antibiotic biosynthesis. Philos Trans R Soc Lond Biol Sci 1991;332(1263):107-114. DOI: 10.1098/rstb.1991.0038.

33. Meyer M, Dimroth $P$, Bott M. Catabolite repression of the citrate fermentation genes in Klebsiella pneumoniae: evidence for the involvement of the cyclic AMP receptor protein. J Bacteriol 2001;183(18):5248-5256. DOI: 10.1128/JB.183.18.5248-5256.2001.
34. Banerjee M. Kinetics of ethanolic fermentation of d-xylose by Klebsiella pneumoniae and its mutants. Appl Environ Microbiol 1989;55(5):1169-1177. DOI: 10.1128/aem.55.5.1169-1177.1989.

35. Keskitalo A, Munukka E, Toivonen R, et al. Enterobacter cloacae administration induces hepatic damage and subcutaneous fat accumulation in high-fat diet-fed mice. PLoS One 2018;13(5):e0198262. DOI: 10.1371/journal.pone.0198262.

36. Kolodziejczyk AA, Zheng D, Elinav E. Diet-microbiota interactions and personalized nutrition. Nat Rev Microbiol 2019;17(12):742-753. DOI: $10.1038 / \mathrm{s} 41579-019-0256-8$. 